\section{THE USE OF NUX VOMICA IN CASES OF CONSTIPATION AND COSTIVENESS.}

By J. Hrde Hougritox, Esq., M.R.C.S.Eng., Surgeon to the Dispensary, Dudley.

[Read before tike Birmingham and Virlland Counties Branch, Feb. 14, 1856.]

Is the daily round of practice there are few cases more annoying to the medical attendant, or less satisfactory in their general management, than cases of habitual constipation and costiveness. We are constantly consulted by patients who tell us that they hardly ever get their bowels to act without medicine; that they have taken senna and salts, and oil, and pills, and various nostrums, each producing its effect for a time, and then losing its power. We travel, perhaps over much the same ground ourselves, with the addition of recommending attention to diet, and exercise, and especially to the calls of nature, and suggest the necessity of endeavouring to bring on a daily habit; in some cases with good result, but, in the majority, without much success; occusionally enemas produce bencfit, but only for a time: and so we find our only resource to be in changes and increased doses of various aperients and purgatives, which, in their turn, go on aggravating the mischief.

If the evil ended here, I trust I should have been justified in bringing the present observations before the Association; but when the results which may arise from the morbid condition referred to are remembered, I feel sure that any attempt to suggest a mode of preventing them will be acceptable.

Dr. Copland says, "the consequences and terminations of constipation require the utmost attention, both as respects their prevention and the recognition of their early approach;" and he enumerates "amongst the most common remote consequences, cutaneous eruptions, headache, vertigo, dyspeptic symptoms, chlorosis, hysteria, chorea, hernia, hæmoptysis ;" and, again, he says, "when constipation is neglected, or improperly treated, the most serious effects are produced upon the bowels themselves-hæmorrhoids, severe colic, passing into ileus or enteritis, being not unfrequent results;" and lastly, " these very serious consequences of constipation may proceed as much from the use of too powerful drastic remedies as from fæcal retention."

Believing, then, from eight or nine years experience, that in nux vomica we have a remedy capable of relieving very many cases of this nature, I have selected this subject for consideration, and proceed at once to detail some cases which will illustrate its powers.

Case I. December 4th. Emma Gibbs, aged 29, came under my care at the Dispensary on October 3rd, suffering from an attack of congestion of the uterus and vagina, which yielded to local depletion, rest, baths, etc. She is naturally of a delicate frame and constitution, and was left very much debilitated by the attack. She got relief to her debility by taking quinine and iron; but during the wholc of the time her bowels were unmanageable and obstinately costive. To relieve this, she has taken, and had given to her, castor oil, senna mixture, pills, and, last of all, pills containing two parts of colocynth and one of henbane. Of these, at first, she took two with relief; then three became necessary, and then four; she then took four at night, and followed it by castor oil in the morning, and thus obtained a motion once in two or three days with much pain and trouble. On the 13th of November I gave her twelve pills, consisting of $3 \mathrm{ss}$ of henbane, $\ni j$ of compound extract of colocynth, and gr. iij of extract of nux romica, and desired her to take one every night, and to continue her tonics as usual. From that time to the present (three weeks) she has taken one pill every night, and had one comfortable motion every morning without the aid of any other aperient, and her health has much improved.

CAgE II. Sarah Silvester, aged 35, applied to the Dispensary on December 16th, suffering from a severe attack of gastrodynia, attended by some derangement of the uterus. I extract the following from my notes. Tongue furred, yellow, indented by the tecth, moist. Appetite bad; violent pain after eating, worse at times; frequent regurgitation of food, sometimes romiting; sometimes she is compelled to produce vomiting before she can get relief after eating. Bowels habitually costive, and very unmanageable. Her habit is to take medicine twice a woek, after which she has two or three stools, and then the bowels do not act again till she again takes medicine. She says she has taken "all sorts of medicine", including many quack pills, for the rclief of her bowels, but only with temporary beuefit, the bowels returning to their inactive state. She had bismuth three times a day, and the pill before named every night.

December 19th. One motion daily, with perfect comfort; she has not been so comfortable in her bowels for years. Gastrodynia and romiting much relieved.

January 16th (thirty-two days). She has taken one pill every night, and had one motion every day with comfort. The pills have nercr missed. Hor stomach symptoms are relieved.

February 13th. She was at the Dispensary to-day. She has taken one pill every night, now two months, and it has never failed.

CASr III. Jan 19th. Anne Evans, aged 18, has been attended at the Dispensary for some time by the housesurgeon on account of costiveness. Her health in other respects is good. She had taken a variety of pills herself, and she had had some at the Dispensary, and lastly, a mixture containing $\zeta^{i j}$ of salts and $z_{i j}$ of essence of senna in half a pint of peppermint water, which have purged her, and left her bowels more sluggish than ever. She was ordered to take a nux vomica pill every night.

February 6th. She has taken a pill every night, and had a comfortable stool every morning, and her health is much better. She never found any medicine to act so well.

February 12th. The bowels have acted daily by taking one pill.

Case Iv. Nov. 19th. Eleanor Jones, aged 40, has been under my care at the Dispensary for an attack of dyspepsia during the last month. The symptoms have gradually yielded to simple treatment, with the exception of costiveness, which has been very troublesome. She has taken various apcrients without much success, and to-day I gave her the nux vomica pill.

November 14th. She took one pill every night, and had her bowels comfortably relieved every morning.

I could multiply cases similar to the preceding ones almost indefinitely, but it would be tedious, and for my purpose unnecessary. I will, therefore, pass on to some of a much more serious nature, in which the powers of the drug are equally evident, and much more important.

It is perhaps needless to draw attention to the fact that the small dose of colocynth used must, by itself, have been entirely inoperative after the failure of larger doses, and of other medicines equally powerful, had its action not been promoted by the addition of some other potent remedy ; that remedy, however, as I shall presently show, not in itself possessing purgative qualities, but the power of rendering the bowels susceptible of the stimulus of very minute doses of aperients.

CASE V. I am indebted to my friend and colleague, Mr. S. D. Fereday, for the following excellent case :-

"Obstinate continuous Constipation: good effects of $N u x$ Vomica. A lady, aged 55 years, corpulent, inactive, and self-indulgent, sent for me on the 12th December, 1845. She had married late in life, and had no family; she was hereditarily predisposed to affections of the stomach and bowels, and had herself for some years suffered much from constipation, having frequently gone four or five days without an evacuation. She had had much advice upon her case, and had not obtained permanent or effectual relief to her symptoms, and she felt convinced that her bowels would not be moved at all without the assistance of medicine. Enemata had been tried without success, they having produced uncomfortable, and even painful distension of the bowels, without being followed by any satisfactory evacus- 
tion. At times, the frecal discharge had been noticed to have a fiattened appearance, always required some straining, and was often passed with force; a digital examination of the rectum did not detect any narrowing of the gut, and she did not suffer from hæmorrhoids.

"She is troubled frequently with small ulcers about the tongue, which are exceedingly painful, and she has frequent headaches, accompanied by much languor and oppression. To remedy this state of things, her medical attendant had been in the habit of giving her occasionally a calomel pill at night and $a$ dose of senna and salts the next morning, which generally acted so violently, that she was compelled to keep her bed the day after taking it. This plan having been carried on for some months, without any improvement, but rather the reverse, she was induced to try something else. At first, after carefully regulating her diet, enjoining exercise, and so forth, I ordered some small doses of blue pill, with colocynth, and one grain of ipecacuanha, at bedtime; by taking which she had a comfortable evacuation the following day. This medicine seemed to answer well for a time, as, she told me, others had done; but gradually failing in their effect, she had been obliged to resort to something of a more active nature. She now further told me that she had not gone to bed for many years without taking some form of physic; and as it appeared to me that the constipation was arising from deficient nerrous energy - the alimentary canal partaking of that which appeared so prominent a feature in her system-I was resolved to try nux rornica, combined with some simple aperient. The success of the medicine, I may say, has been perfect for upwards of nine years. She has not gone to bed a single night without taking it (except when she has been ill, and required other treatment), neither has she passed a single day without an easy evacuation; and there is one peculiar feature I would mention, that the same dose is as effective noro as it was nine years ago. Being strongly impressed with the good effects of nux romica in general inaction of the bowels, as safe and lasting, I could cite several cases from memory, but this one made so strong an impression upon my mind that I fear others would lose by comparison."

CAsE vi. In July 1852, I was called upon to see a lady (Mrs. B.) who was suffering, as she supposed, from some mechanical obstruction to the passage of the contents of the alimentary canal, though she had not any idea of the precise situation of the obstruction. She was about 50 years old, the mother of a large and healthy family, had had good labours, and always enjoyed unusually good health till 1849. Her present symptoms first began to develope themselves during the prevalence of cholera in that year, as she herself imagines, from taking a good deal of brandy, which (having the greatest dread of the epidemic) she had done under the impression that it would protect her from its influence. Her usual habits, before and since that time, are abstemious, amounting almost to teetotalism. Her first complaint was of constipation, which speedily gave way to some simple medicine, and then recurred; again yielded, and again recurred. This state continued to grow worse, and various changes in the nature, strength, and quantities of the purgatives became necessary. Enemas were then had recourse to, and were carried so far as to produce such irritation that she was compelled to relinquish their use. She was under the care of a most respectable practitioner, but one who, unfortunately for her, had more faith in calomel, colocynth, black dose, and their associates than now falls to the lot of most of us. These were used with the utmost vigour; and when I saw her first, she had pills marked "calomel pills", pills marked "colocynth pills" and an enormous bottle of senna mixture; and she had general instructions to ring the changes on these and castor oil and the enema until the desired effects were produced.

During the treatment, Sir B. Brodie had been consulted as to the state of the rectum, and Dr. Rigby as to the state of the uterus, to see if there was any obstruction in the former, or any caused by the latter. I did not ascertain the result of her consultation with Sir Benjamin, but Dr. Rigby advised her to take olive oil freely. Several other persons, some of considerable eminence, were consulted, but no material relief had been procured. Her life had become one of great misery, for the little comfort she got whilst her bowels were allowed to remain quiet was destroyed by her fears of the next necessary resort to medicine.

It was when under the influence of large doses of calomel and black draught that I first saw her, and her condition was then deplorable. She was suffering from some degree of fever, a thickly conted white tongue, thirst, nausea, and terrible pain, with distension of the whole abdomen. Her bowels were acting very imperfectly, the evacuations being fluid, greeuish, and scanty, and mixed with large flakes of tenacious ropy mucus, and sometimes a little blood. She was, moreover, in a state of great mental excitement, impressed with the idea that she had stricture high up, and that this attack would probably be fatal.

My first object was to quiet the irritation existing. and then to carefully examine if there was any evidence of mechanical obstruction; failing which, I assured her that she had everything to hope for. About the fifth or sixth day after I saw her, I gave her the nux vomica, combined with minute doses of colocynth and henbane; warning her that she must not depend upon the pills for the relief of the bowels at once, and that other aperients might and probably would be necessary for a time. The beneficial effects of the medicine soon became evident, though she required the occasional use of other mild aperients for a time, and does occasionally now. In a month, she went to the sea, and remained there six weeks, improving rapidly in health. From that time to the present, she has taken the pills every night, except when I have stopped them; and at the present time does not suffer more from her bowels than hundreds of persons who consider themselves in perfect health. She enjoys excellent health, and is a remarkably fine healthy-looking woman for her years. She seldom has occasion to take any other medicine, has very little pain in the bowels, and never passes any blood or ropy mucus.

Case vir. Mrs. J. 0., aged 45, consulted me on the 15 th October, 1855. Constitution good ; secretions natural; pulse 76 , feeble; urine free, often passed with much pain and irritation; tongue furred with a yellowish fur, rather dry ; no thirst; appetite pretty good; dyspepsia severe, if she does not observe strict rules of diet; bowels confined; stools passed without much pain, never without medicine, followed by an enema; motions solid and triangular, and often mixed with great quantities of mucus; frequent severe headaches; no chest symptcms ; palpitations at times; violent pain in the sacrum, and round the brim of the pelvis; no bearing down; profuse leucorrhœa, purulent ; menses regular, not painful; discharge healthy. She suffers greatly from piles. Had nine children very fast, the youngest six years old. Never miscarried. Health always good till after she ceased to bear children, though she was considered delicate. Her present difficulty with her bowels commenced three or four years since, and to alleviate it she has been always taking various aperients, and using injections. Her uterine symptoms have existed for ten or twelve years, but she has never undergone any examination, though she has been recommended to use nitrate of silver injections, which have afforded her much relief; but the bowels are her chief difficulty, and with reference to their condition my advice was asked. I had an opportunity of examining one of the membranous substances she was constantly passing. Whilst floating in water, it looked like a false membrane gradually fading away into a distinct mucous cloud. The more solid parts of this membrane had a distinctly marked pink colour. I took this membrane home with me, wrapped in a little linen rag; in a few hours it had entirely lost its membranous appearance, and broke up into small shreds. Dr. Heslop, who examined part of it, said that it consisted of plasma thrown off by the mucous membrane, contdining a few cells. Extract of henbane $\ni i j$; compound extract of colocynth $\ni j$; extract nux vomica gr. iij; divide into twelve pills, and take two every night. Moderate exercise, followed by the recumbent position, and careful diet. No other medicine. 
Sept. 21st. The bowels have acted daily, without other medicine or enema. She does not pass any mucus, and feels much better. To take one pill only.

Oct. 29th. Daily relief to the bowels without other medicine. The motions are passed without pain. Pain in the back better; leucorrhœea better; tongue improred; appetite better; pain in the stomach after eating; no flatulence. Last night she forgot her pill, and this morning she had no evacuation till she had had an enema. She has not passed any membrane since the last report. A carminative mixture.

Dec. 4th. During the last six weeks, it has been two or three times necessary to take an additional pill of three grains of colocynth, as the bowels have become a little sluggish; the dose of nux vomica remaining unaltered. This has been sufficient for the purpose.

I have no further note on this case; but as the lady continues to send regularly for her pills, I conclude they continue to act beneficially.

There is a considerable resemblance between the two last cases. In each the disease had been gradually increasing ; in each it had appeared at a time near to the decline of the menses; in each the bowels had been worried by purgatives into a state of the greatest obstinacy; and in each the mucous membrane was in a state of dangerous excitement, as evidenced by the quantity of ropy mucus; in one case, if not on both, approaching to false membrane. It will be admitted that in each of these cases danger was imminent, if not absolutely present; yet the relief in both was signal-not by giving medicine, but by taking it away; for I do not conceive that the relief was the effect of the nux romica, but of the withdrawing of the violent irritation resulting from calomel, colocynth, black dose, etc.; which, however, the nux vomica enabled us to do.

Case viri. George Harrisson, aged 61, applied to the dispensary December 16th, 1855, suffering from an attack of partial hemiplegia. His bowels acted regularly. He was ordered to take one-third of the extract of nux vomica alone three times a day; and he has continued to do so till Feb. 2nd, in all forty-six days, when the following note was made:- "He continues in good health, and the power over his limbs is much increased." He has not observed any difference in the state of his bowels since he commenced taking the pills, though he has taken them punctually: nor has he observed any unpleasant symptom. I have observed other cases in which the drug alone has not influenced the state of the bowels.

Hence it appears, from the foregoing observations, that nux romica does not itself possess aperient properties, but that it has the power of influencing or probably increasing the action of other aperients, or what seems most probable, of rendering the intestinal mucous membrane susceptible of their influence by giving energy to its nerves.

Authorities are very silent on the peculiar property of the nux romica which I am now discussing. The last edition of the Pharmacopaia Londinensis dismisses the whole matter in these laconic words: "Use-in some cases of paralysis."

Pereira does not allude to it, though he speaks of the efficacy of the drug in "dyspepsia, pyrosis, and some forms of dysentery".

Dr. Copland, whose mind seems to have embraced almost everything in medical science, says: "In cases apparently depending on deficient tone of the muscular coat of the large bowels, and imperfect propelling power of the upper part of the rectum, I have seen benefit from combining the extract of nux vomica with the pilula aloes c. myrrha or compound extract of colocynth."

Dr. Neligan, in his exccllent treatise On the $C^{\prime}$ ses and Modes of Administration of Medicines, observes: "I have used the extract of nux vomica with much advantage as an addition to purgatives in constipation depending on want of tone in the muscular coat of the large intestines, one of the most frequent causes of this state in females, and one which is distinctly characterised by great secretion of flatus, and colicky pains which accompany it."
So far as I have been able to learn, we are indebted to Magendie for the first suggestion on the powers of the nux romica. In 1845, Dr. Tessier, of Lyons, published a paper which was quoted in the Lancet, and in which he says that " he considers it particularly indicated in cases where there is reason to suspect general want of tone in the bowels, as in paralytic and old persons, or where we suspect want of tonc of the muscular coat, in consequence of great and long continued distension; or, in short, where the constipation can be referred to an undue secretion of gas, which in itself, by causing distension of the bowels, diminishes their contractile power."

In the JodRNAL of this Association for May 1848 is an article by Mr. Boult of Bath, on the employment of nux vomica in habitual constipation, in which he observes: "I first tried the extract alone, in half-grain doses, two or three times a day, and was disappointed with the result. I was then led to use the extract in combination with aloes, whubarb, and scammony; and was surprised at the result." Mr. Boult seems to think that it has the power of incrensing the action of other purgatives; and he says: "Generally speaking, a pill containing three-quarters of a grain of Barbadoes aloes, three-quarters of a grain of extract of rhubarb, and half a grain of extract of nux romica, taken at bed-time, will produce one or two full evacuations the next morning." And he continues: "I have prescribed the pill already mentioned for montis together, and at the end of that time the effect has been produced as certainly as at first, and no bad consequence has arisen: on the contrary, I think it will be found that, when the medicine is discontinued, the tendency to costireness will be found to be diminished."

The correspondent of the Medical Gazette, November 10th, 1855, in his Notes on Hospital Therapeutics, has the following admirable remarks on the subject: "Among the conditions over which nux vomica, and its active principle, strychnia, possess most useful powers, is that of habitual constipation from muscular atony of the intestinal tube. At the City Hospital for Diseases of the Chest, wc observe that Dr. Peacock and Dr. Andrew Clarke are both in the habit of frequently resorting to it for this purpose. It is generally given in combination with the compound rhubarb pill, and in doses of the extract of from one-sixth to one-half a grain. Of itself it can scarcely be deemed an aperient; that is, it does not so much excite peristaltic action as supply tone to the weakened muscular coat, by which it is enabled to reply efficiently to other irritants. Hence the need of combination with aloes, rhubarb, or some similar drug."

Dr. Peacock has mentioned to us a case in which a man of feeble intellect and torpid nervous system generally had derived great benefit from its employment. At first, the bowels were obstinately costive, and lavements produced no action; but since the use of nux romica they have so far increased in power and susceptibility that simple injections are quite sufficient to procure all the action that is necessary.

With the observations quoted I generally concur, but specially with those of Mr. Boult and of the correspondent of the Medical Gazette.

From the facts and opinions adduced I think we may safely infer-

1. That in the nux vomica we have a new agent in the treatment of constipation: not a purgative or aperient, but a substance which, added to very minute doses of various purgatives and aperients, forms a kind of tertium quid, which combines the advantages of purgatives without the disadvantages, which does not leave the bowels debilitated and indisposed to act after its operation, but which, on the contrary, imparts tone, rendering their action more certain.

2. That the agent does not lose its power by continued use.

3. That it is a perfectly safe remedy when used in the mode suggested.

4. That it is not an accumulative medicine.

I fear, sir, that I have trespassed very long on your time 
in comidering a question apparently 80 simple and commonplece 2 that of constipstion; but when $\nabla e$ consider the results to which I have alluded, the numbers of persons who suffor from it in greater or less degrees, and hence the misery and suffering it entails on humanity generally, I trust that it will not be considered that I have dilated too much, or magnified the importance of the subject; and that, in fact, I have not been " breaking a fly on a wheel".

\section{Assoriation eftleorad ofournal.}

SATURDAY, APRIL 5TH, 1856.

\section{POSTPONEMENT OF MR. HEADLAM'S BILL.}

ThE committal of Mr. Headlam's Bill was on Wednesday last postponed for a week, and it is by no means impossible that this postponement may lead to still further delay. But our readers have no occasion to imagine that the exultation of the enemies of the Bill, who are already celebrating their song of triumph orer its extinction, is by any means so well founded as they choose to fancy. On the contrary, it will not surprise us if this very delay should lead ultimately to the success of the measure.

We will briefly state the facts as they occurred. Up to Tuesday evening, Government had given no sign of any opposition to the Bill; on the contrary, Mr. Headlam had been led to suppose, and that in the direct word of the Home Secretary, that he might look forward to Government support in case of a hostile division. But, on the evening preceding the committal of the Bill, an intimation was conveyed to the hon. gentleman that the President of the Board of Health, as the organ of the Ministry, would more an amendment on the proposed constitution of the Council.* To this intimation, Mr. Headlam replied that he had no objection to any reasonable modification of the Council, especially as to a reduction of its numbers, but that he would not abandon the representative principle; he added that, if a Council composed of Government nominees alone were proposed, he should divide the House against it.

On rising in the House on Wednesday morning, to announce that "the Speaker do now leave the chair", Mr. Headlam presented a very large number of petitions from all parts of the country, in favour of the Bill ; - a tolerable refutation of the absurd assertion that his measure never had, or has not now, the support of the main body of the profession. Other members presented petitions to the same effect; one member alone bringing up no fewer than sixand-thirty. After a few feeble observations from Lord Robert Grosvenor, to whose proposition of postponement Mr. Headlam very properly refused to consent; and after some desultory conversation among a number of M.P.s, who

- The amendment to be moved by Mr. Corper in bebalf of the Govern mont, which would entirely alter the composition of the Conncil, was entered so follows upon the motion paper :-

Clause 5. Her Majesty may, with the advice of the Privy Conncil, appoint three of such persons as aresaid to be members of the Mediegl Council for a term of four years, three of such members for a term of five Jears, and three for a term of six years; and unon every vacancy among the members of the Council and their successors, Her Majesty may, with the adreo or tho Privy Council, appoint another person to fll such vacancy. moject to the above-mentioned qualincatiou, and every member appointed by Her Majesty to fill a racancy occasioned by the expiration of the term of omce shall be appointed for the term of four years; and every member eppointed to supply the plece of a member whose office shall have become roid otherwise than by the expiration of his term of offee, shall be appointed tor the remaiuder of the term of offce of such last-mentioned member. showed a remarkable ignorance of the subject on which they poured forth their wisdom, Sir George Grey rose, and adrised the House to go into Committee. He explainedor rather endeavoured to explain-the lateness of the notice which the Government had given of their intended alteration, by affirming that only on the day before had he become acquainted with the objections to the proposed Council. On this, Mr. Walpole mored that the committal of the Bill should be postponed till the following week, that the proposed amendment might be considered; and various members, hostile to the Bill, of course backed up the specious appeal. On this, Sir George Grey again rose, deliberately ate his own words, spoken ten minutes before, and declared against the committal of the measure. In other words, the Home Secretary stated that, because the Government had the night before put an amendment on the votes of the House, therefore the Government objected to the committal of the Bill. In other words, he enunciated a proposition which, if carried out, must infallibly prevent any measure of any independent member from ever being considered in Committee, if the ministry of the moment happen to be hostile to it.

Certainly no measure, whether public or private, can pass, if placing an amendment on the rotes the night before the committal is to constitute a reason for not proceeding with the Bill. Out of the 656 members of the House, there will nerer be any difficulty in finding some one to adopt the dodge.

The hardship, not only to Mr. Headlam, but to the medical profession, in postponing the Bill onthis paltry pretext, was forcibly pointed out by Sir John Pakington. The thanks of our profession are due to Sir John, for the manly tone which he adopted on the occasion; and his remarks, coupled with the undecided tone of the Home Secretary, will perhaps add an additional argument to support the feeling which has grown up of late, in more than one quarter, that those who desire practical reforms would lose nothing by a change of ministry.

In consequence of the desertion of Mr. Headlam by the Ministry, who voted against the committal of the Bill, thereby just turning the scale of a close division, the measure was postponed by 116 to 81 . This large minority shows our parliamentary strength. Mr. Walpole has given notice of a motion to refer the Bill to a Select Committee; but it is by no means certain that this proposition will be acceded to. There is a strong feeling in the House that Mr. Headlam has been ill used, and that his Bill has not yet had fair play. But, even if the Bill bo so referred, there will probably be little reason for regret, except for the delay that will ensue. Truth is great, and will prevail. The nonsense and misrepresentation respecting the Bill which have been talked and written lately, will be surely exploded; the necessity for some legislation will be made apparent; and, when the subject is fully and fairly discussed, the conclusions of our Reform Committee will be appreciated as they deserve.

In the meantime, we strongly urge on all supporters of the Bill to communicate with their representatives in Parliament; to protest strongly against the unfair conduct of the Government; and, in short, to agitate in every way in support of Mr. Headlam, who has stood manfully by the interests of the great body of the profession, and has been bitterly opposed because he has done so. 